\title{
EBP50 gene transfection promotes 5-fluorouracil-induced apoptosis in gastric cancer cells through Bax- and Bcl-2-triggered mitochondrial pathways
}

\author{
XIAO-GUANG LV*, MENG-YAO JI*, WEI-GUO DONG, XIAO-FEI LEI, MENG LIU, \\ XU-FENG GUO, JING WANG and CHUO FANG \\ Department of Gastroenterology, Renmin Hospital of Wuhan University, Wuhan, Hubei 430060, P.R. China \\ Received November 18, 2011; Accepted February 17, 2012
}

DOI: $10.3892 / \mathrm{mmr} .2012 .805$

\begin{abstract}
Fluorouracil (5-FU) plays an important role in the chemotherapy of advanced gastric cancer. However, genetic factors that affect therapeutic efficacy of 5-FU warrant further investigation. In the present study, using stable transfection of the ezrin-radixin-moesin-binding phosphoprotein 50 (EBP50) gene, we explored the genetic influences on 5-FU-induced apoptosis of human gastric cancer cells. Stable overexpression of the EBP50 gene was determined by reverse transcription polymerase chain reaction (RT-PCR) assay and western blot analysis. After treatment with 5-FU, cell growth activities in vitro were investigated by MTT assay. Cell apoptosis was evaluated by Hoechst 33258 staining and flow cytometry of Annexin V-FITC/PI staining. Compared with the BGC823 or BGC823/neo cells, EBP50 mRNA and protein levels in the BGC823/EBP50 cells (EBP50-transfected BGC823 cells) were markedly higher. Chemosensitivity and apoptosis rates of the BGC823/EBP50 cells were higher compared to the BGC823 and BGC823/neo cells following treatment with 5-FU. Stable overexpression of extrinsic EBP50 distinctly increases the 5-FU-induced apoptosis of gastric cancer cells, and is a novel strategy by which to improve the chemosensitivity of gastric cancer to 5-FU.
\end{abstract}

\section{Introduction}

Gastric cancer is an extremely common disease worldwide and is the second most frequent cause of cancer-related death, affecting approximately one million individuals per year. The highest incidence, 69 cases per 100,000 people annually, is

Correspondence to: Dr Wei-Guo Dong, Department of Gastroenterology, Renmin Hospital of Wuhan University, Wuhan, Hubei 430060, P.R. China

E-mail:dwg@whu.edu.cn

*Contributed equally

Key words: ezrin-radixin-moesin-binding phosphoprotein 50 gene, 5-fluorouracil, apoptosis, gastric cancer found in males of Northeast Asia (Japan, Korea, and China) (1). Preoperative or neoadjuvant chemotherapy potentially downstages advanced gastric cancer and improves resectability and survival.

A significant survival benefit of 5-fluorouracil (5-FU)-based chemotherapy for metastatic gastric cancer compared with best supportive care has been reported $(2,3)$. In Western countries, 5-FU combined with cisplatin and cisplatin plus epirubicin have been referred to as the standard chemotherapy for metastatic gastric cancer, with a median survival rate ranging from 7.3 to 10.5 months (2). In China, 5-FU monotherapy still remains the reference arm of clinical trials for metastatic gastric cancer (3). Combined surgery and chemotherapy with 5-FU/ cisplatin, is considered as the standard therapy for advanced gastric cancer. At present, 5-FU is one of the most commonly used chemotherapeutic agents. Despite these advances, drug resistance remains a problem in regards to the clinical use of 5-FU. With the advent of novel technologies, specific genes have been identified to be involved in mediating resistance to 5-FU (4). It is important to clarify the molecular mechanisms linked to the chemosensitivity of 5-FU.

Ezrin-radixin-moesin-binding phosphoprotein 50 (EBP50) is a post synaptic density-95/Disk-large/ZO-1 homologous domain-containing protein that is involved in the linkage of integral membrane proteins to the cytoskeleton and plays an important role in cell signaling (5). Overexpression of NHERF1/EBP50 has been reported in breast cancer $(5,6)$ and in $55 \%$ of hepatocellular carcinoma samples (7). Initially, overexpression of NHERF1/EBP50 has been correlated with lower tumor invasiveness in breast cancer cell lines (8). These two independent studies however reached the same conclusions. They found that EBP50 overexpression is significantly associated with tumor stage, metastatic progression, poor prognosis and ER status $(5,9)$. The expression and distribution of EBP50 are regulated by estrogens and contribute to the proliferative response in biliary epithelial cells (10). We discovered that EBP50 is a novel marker for gastric adenocarcinoma and is involved in the proliferation, migration, and invasion of gastric cancer cells. Little attention has been paid, however, to the relationship between EBP50 and 5-FU chemosensitivity.

In the present study, we investigated whether EBP50 plays a role in 5-FU-induced apoptosis in gastric cancer cells. To test 
this hypothesis, we constructed a BGC823/EBP50 cell line using G418 selection in human gastric cancer BGC823 cells. Cellular responsiveness to 5-FU was examined with various assays in both non-transfected BGC823 cells and EBP50transfected BGC823 cells.

\section{Materials and methods}

Cell culture and plasmids. Human gastric cancer cell line, BGC823, was purchased from Shanghai Cell Collection (Shanghai, China) and cultured in a $5 \% \mathrm{CO}_{2}$ and $95 \%$ humidified atmosphere, in RPMI-1640 medium (Gibco-BRL, Grand Island, NY, USA), supplemented with $10 \%$ fetal bovine serum (FBS) (Gibco-BRL). Cells were split every 3 days to observe for logarithmic growth. The pBK-CMV-HA-EBP50 plasmid was kindly provided by Dr Randy Hall of Emory University (Atlanta, GA, USA).

Stable transfection. Cells were transfected with the pBKCMV-HA-EBP50 plasmid or pBK-CMV-HA vector using Lipofectamine $^{\mathrm{TM}} 2000$ (Invitrogen Corp., Carlsbad, CA, USA) following the manufacturer's protocol. After $24 \mathrm{~h}$ of transfection, cells were trypsinized and reseeded into $10-\mathrm{cm}$ culture dishes at a density of $2 \times 10^{4}$ cells/well. Stable transfected cells were obtained by using selection medium (culture medium with $200 \mu \mathrm{g} / \mathrm{ml} \mathrm{G} 418$ ). Single-cell clones were isolated for clone expansion. Each cell clone was screened by western blotting to determine the exogenous level of EBP50 protein expression. Next, cell clones were cultured and amplified in a RPMI-1640 medium supplemented with 10\% FBS and $200 \mu \mathrm{g} / \mathrm{ml} \mathrm{G} 418$.

MTT assay. Cell proliferation was assessed with MTT (SigmaAldrich LCC, St. Louis, MO, USA) colorimetric method. Gastric cancer cells were cultured in a 96-well plate in the presence of 0.1 to $10.0 \mathrm{mg} / \mathrm{l} 5-\mathrm{FU}$ for 0 to $24 \mathrm{~h}$. MTT reagent was added to each well and incubated for 2 to $4 \mathrm{~h}$ at $37^{\circ} \mathrm{C}$. After the purple precipitate was visible, the cells were added together with $150 \mu \mathrm{l}$ isopropanol/0.04 $\mathrm{M} \mathrm{HCl}$ and incubated at room temperature in the dark for $2 \mathrm{~h}$. The absorbance was recorded at $570 \mathrm{~nm}$. For the detection of each, the complete procedure was repeated three times.

\section{Analysis of cell apoptosis}

Hoechst 33258 staining. Apoptotic cells were detected by Hoechst 33258 staining as follows. BGC823 cells were treated with $0.1,1.0$ and $10.0 \mathrm{mg} / \mathrm{l} 5-\mathrm{FU}$ for $24 \mathrm{~h}$, and then incubated with $20 \mu \mathrm{M}$ Hoechst 33258 (Sigma-Aldrich LCC) for $10 \mathrm{~min}$ at room temperature. The cells were then washed twice with PBS and observed under a fluorescence microscope (Nikon, Tokyo, Japan). Apoptotic features were assessed by observing the staining of chromatin condensation and fragments in nuclei using Hoechst 33258. For each case, ten random fields were counted.

Flow cytometry. After treatment with $10 \mathrm{mg} / \mathrm{l} 5-\mathrm{FU}$ for $48 \mathrm{~h}$, apoptotic ratios of BGC823, BGC823/neo and BGC823/ EBP50 cells were determinated by Annexin V-FITC and propidium iodide (PI) (BioVision, Inc., Mountain View, CA, USA) staining and flow cytometry. Cells from the aforementioned groups were collected, washed twice with cold PBS, resuspended with $100 \mu \mathrm{l}$ binding buffer into $5 \times 10^{5}$ cells $/ \mathrm{ml}$, and incubated with Annexin V-FITC at room temperature for 15 min. After washing with a binding buffer, the cells were resuspended with $500 \mu \mathrm{l}$ binding buffer containing $10 \mu \mathrm{l} \mathrm{PI}$ $(20 \mu \mathrm{g} / \mathrm{ml})$, and incubated on ice for $30 \mathrm{~min}$. Apoptosis was analyzed by flow cytometry at a wavelength of $488 \mathrm{~nm}$. For each detection, the total procedure was repeated 3 times.

Western blot analysis. Levels of protein expression were analyzed by western blot analysis. Briefly, cells were washed with PBS and lysed in lysis buffer $(20 \mathrm{mM}$ Tris- $\mathrm{HCl}$, $\mathrm{pH} 7.4,150 \mathrm{mM} \mathrm{NaCl}, 0.5 \%$ Nonidet P-40, 1 mM EDTA, $50 \mu \mathrm{g} / \mathrm{ml}$ leupeptin, $30 \mu \mathrm{g} / \mathrm{ml}$ aprotinin and $1 \mathrm{mM}$ PMSF). A total volume of $40 \mu \mathrm{g}$ of protein was loaded per lane and separated on $12.5 \%$ sodium dodecyl sulfate polyacrylamide (SDS-PAGE) gels and then transferred to a nitrocellulose membrane (Millipore Corp., Bedford, MA, USA) using wet transfer system (Bio-Rad Laboratories, Inc., Hercules, CA, USA). The membrane was blocked with $10 \%$ nonfat dry milk in TBST and then incubated with the following primary antibodies: procaspase-9, cleaved caspase-9, procaspase-3, cleaved caspase-3, and GADPH (Santa Cruz Biotechnology, Inc., Santa Cruz, CA, USA) overnight at $4^{\circ} \mathrm{C}$. The following dilutions were used: procaspase- $9(1: 1,000)$, procaspase- 3 $(1: 1,000)$, cleaved caspase- $9(1: 1,000)$, cleaved caspase- 3 $(1: 1,000)$, Bax $(1: 2,000), \operatorname{Bcl}-2(1: 3,000)$ and actin $(1: 1,000)$. After three washes with TBST, the membranes were incubated with biotinylated goat anti-rabbit IgG secondary antibody (Promega Corp., Madison, WI, USA; 1:3,000 dilution) for $1 \mathrm{~h}$ at room temperature and then developed with the use of an enhanced chemiluminescence (ECL) system (Millipore) and then exposed to Kodak X-ray film (Kodak, Rochester, NY, USA). Protein band intensities were determined densitometrically using the video imaging CMIASWIN system (Bio-Rad).

Statistical analyses. All data are expressed as means \pm SD. The means of the different groups were compared using one-way ANOVA test. All statistical analyses were performed with SPSS13.0 software (SPSS, Inc., Chicago, IL, USA). Significant differences were accepted at P-values $<0.05$.

\section{Results}

Construction of the $p B K-C M V-H A-E B P 50$ vector and overexpression of EBP50 in BGC823 cells. The recombinants, pBK-CMV-HA-EBP50, were validated by DNA-sequencing analysis and restriction-endonuclease analysis. All untransfected BGC823 cells were dead after G418 $(200 \mu \mathrm{g} / \mathrm{ml})$ selection for 1 week. The pBK-CMV-HA-EBP50-transfected cells were continuously selected with G418 for 4 weeks, until magnificent clones were observed. The clones were respectively amplified. The subclone BGC $823 /$ neo cells and BGC823/EBP50 cells were obtained. To investigate the mRNA and protein expression of EBP50 in the BGC823, BGC823/neo and BGC823/EBP50 cells, the levels of EBP50 were measured by RT-PCR assay and western blot analysis. The relative expression of EBP50 to actin is shown. The mRNA and protein levels of EBP50 in the BGC823/EBP50 cells were significantly greater than levels in the BGC823 and BGC823/neo cells $(\mathrm{P}<0.05)$. No difference was noted between 
A
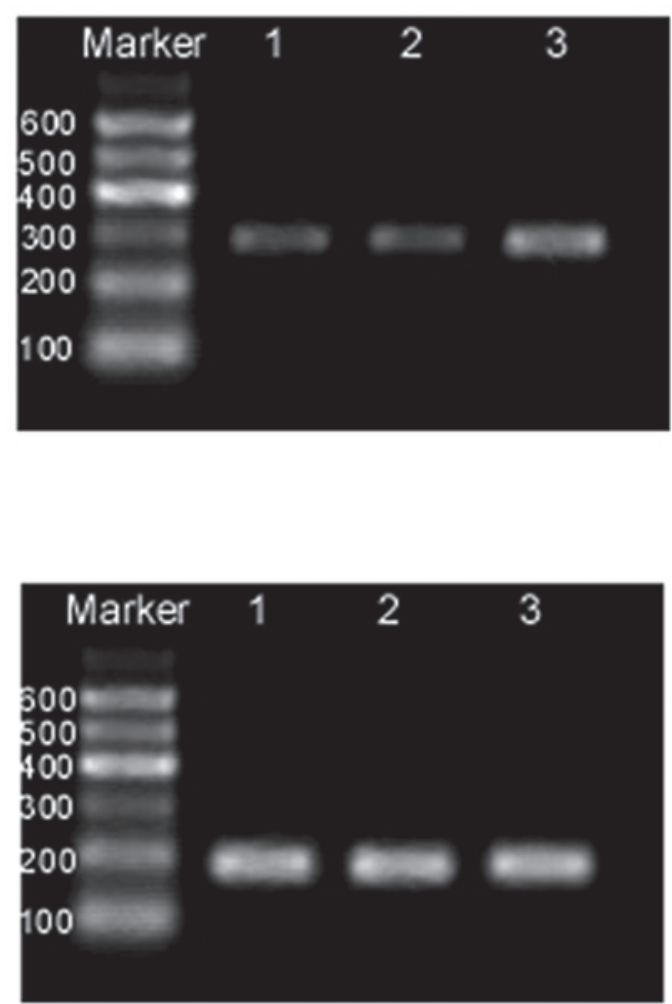
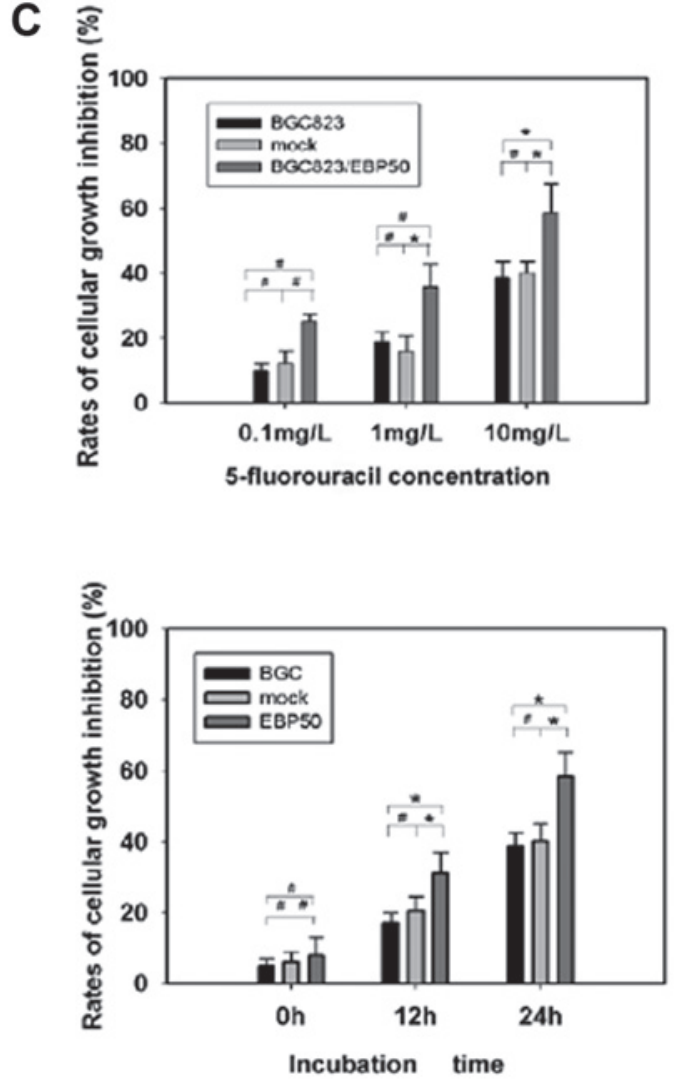

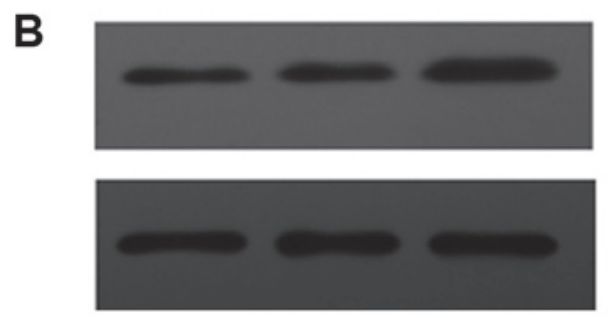

Figure 1. (A) Expression of EBP50 mRNA was detected by RT-PCR. (B) Expression of EBP50 protein was detected by western blot analysis. Lane 1, BGC823 cells; lane 2, BGC823/neo cells; lane 3, BGC823/EBP50. Actin expression was used as an internal control for mRNA and protein, respectively.(C) EBP50 overexpression promoted the inhibition rates of cellular growth. BGC823, mock and BGC823/EBP50 cells were treated with different concentrations of 5-FU $(0.1,1.0,10.0 \mathrm{mg} / \mathrm{l})$ for different time periods $(0$ to $24 \mathrm{~h})$. The inhibition rates of cell growth were detected by MTT assay (n=5). Data are shown by mean \pm SE. $\left(\right.$ P $\left.<<0.05 ;{ }^{*} \mathrm{P}>0.05\right)$.

the BGC823 and BGC823/neo cells in terms of the brightness of the EBP50 bands (P>0.05) (Fig. 1A and B).

Cellular sensitivity to $5-F U$. To study cellular sensitivity to 5-FU, BGC823, BGC823/neo and BGC823/EBP50 cells were exposed to various concentrations $(0.1,1.0$ and $10.0 \mathrm{mg} / \mathrm{l})$ of 5-FU for different durations (0, 12 and $24 \mathrm{~h})$. Rates of cellular growth inhibition were measured by MTT assay. As shown in Fig. 1C, overexpression of EBP50 promoted the inhibition of the cellular growth rate in the BGC823/EBP50 cells compared with these values in the BGC823 and BGC823/mock cells. No difference in growth inhibitory rates between BGC823 and BGC823/neo cells were noted ( $>>0.05)$.

Overexpression of EBP50 enhances 5-FU-induced apoptosis and its mechanism in BGC823 cells. BGC823, BGC823/neo and BGC823/EBP50 cells were exposed to 5-FU for various durations ( 0,12 and 24 h). First, morphological changes indicative of apoptosis such as chromatin condensation and nuclear fragmentation were analyzed by Hoechst 33258 staining assay (Fig. 2A). We found that the overexpression of EBP50 induced a higher percentage of cell apoptosis in BGC823/ EBP50 cells (12 h, 12.9 $\pm 7.8 \% ; 24 \mathrm{~h}, 27.8 \pm 5.1 \%)$ than these values in BGC823 (12 h, 8.6 $3.6 \% ; 24 \mathrm{~h}, 17.4 \pm 6.5 \%)$, and

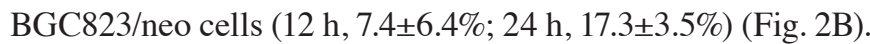
Subsequently, Annexin V-FITC/PI staining was performed and flow cytometry was carried out, which further confirmed that overexpression of EBP50 enhanced 5-FU-induced apoptosis. We observed that overexpression of EBP50 induced a higher percentage of cell apoptosis in the BGC823/EBP50 cells $(12 \mathrm{~h}, 12.9 \pm 7.8 \% ; 24 \mathrm{~h}, 27.8 \pm 5.1 \%)$ compared to the percentage of cell apoptosis in the BGC823 (12 h, 9.7 $\pm 2.7 \%$; $24 \mathrm{~h}, 17.8 \pm 4.6 \%)$ and BGC823/neo cells $(12 \mathrm{~h}, 8.3 \pm 3.5 \% ; 24 \mathrm{~h}$, $24.0 \pm 7.8 \%$ ) (Fig. 3). 
A 5-fluorouracil (dose)

$0.1 \mathrm{mg} / \mathrm{l}$
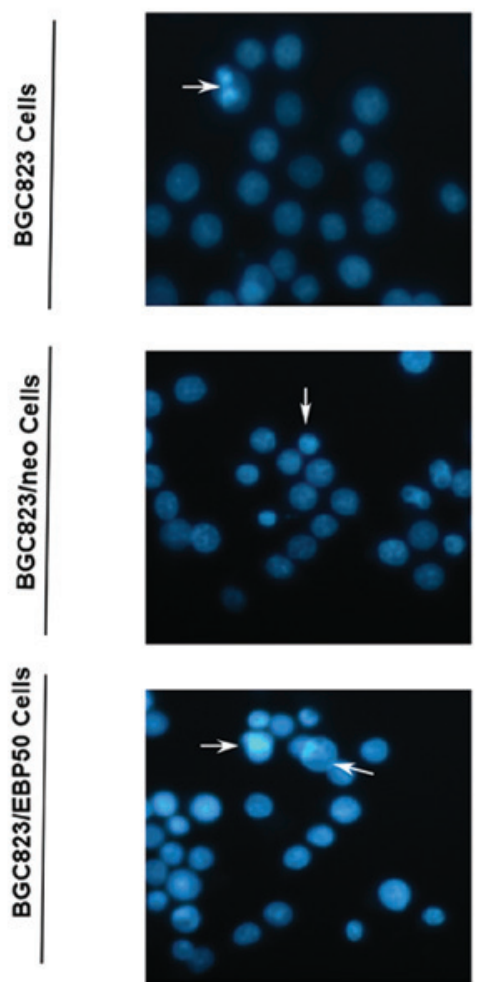

$1 \mathrm{mg} / \mathrm{l}$
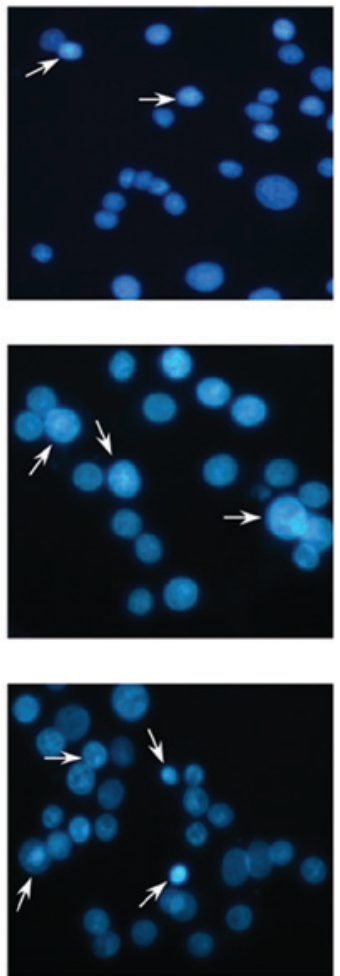

$10 \mathrm{mg} / \mathrm{l}$
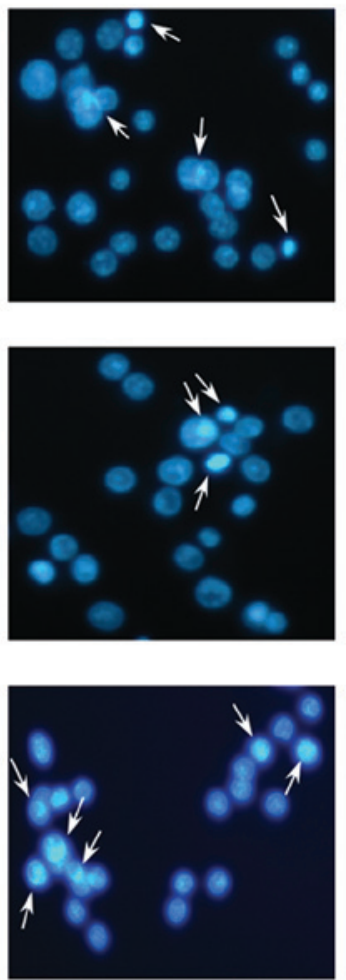

B Detection of cellular apoptosis by Hoechst 33258

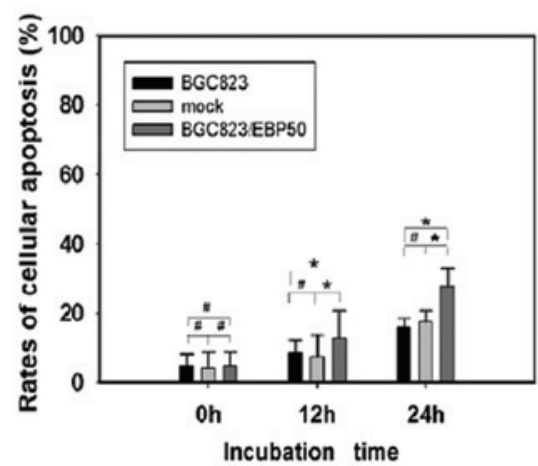

Figure 2. (A) Cellular apoptosis was analyzed by Hoechst 33258 staining. Condensed or fragmented apoptotic nuclei were indicated by white arrows. (B) Data are expressed as the mean $\pm \mathrm{SE}$. $\left({ }^{*} \mathrm{P}<0.05 ;{ }^{*} \mathrm{P}>0.05, \mathrm{n}=5\right)$.

Role of Bcl-2, Bax, and caspase activity in EBP50-enhanced 5-FU-induced apoptosis. We performed a subsequent study to explore the potential mechanism involved in EBP50enhanced 5-FU-induced apoptosis. Activation of Bax, Bcl-2, cleaved forms of caspase-3 and -9 were detected by western blot analysis. Compared with BGC823 and BGC823/neo cells, the activity of Bax, caspase-3 and -9 in BGC823/EBP50 cells treated with 5-FU were highly upregulated $(\mathrm{P}<0.05)$ (Fig. 4). These results suggest that overexpression of EBP50 enhances the activity of caspase- 3 and -9 .

\section{Discussion}

Gastric cancer is still the second leading cause of cancerrelated death worldwide. Chemotherapy is one of the major treatment options for advanced gastric cancer (1). The efficacy of chemotherapy for cancer is poor due to insensitivity and the development of drug resistance. Serious challenges lay ahead given the complex nature of the cytotoxic metabolism with multiple players working together to influence a drug's effectiveness and toxicity (11). The combined use of molecular-targeted therapy with chemotherapy, however, may provide new opportunities for cancer treatment $(12,13)$. The identification of molecules within an apoptotic pathway will potentiate tumor chemosensitivity that may ultimately enable the optimization of chemotherapy for cancer by enhancing a therapeutic response to chemotherapy and modulating the apoptotic threshold of cancer cells $(14,15)$.

In the present study, the EBP50 gene was transfected into human gastric cancer cell lines, which induced its over- 
A
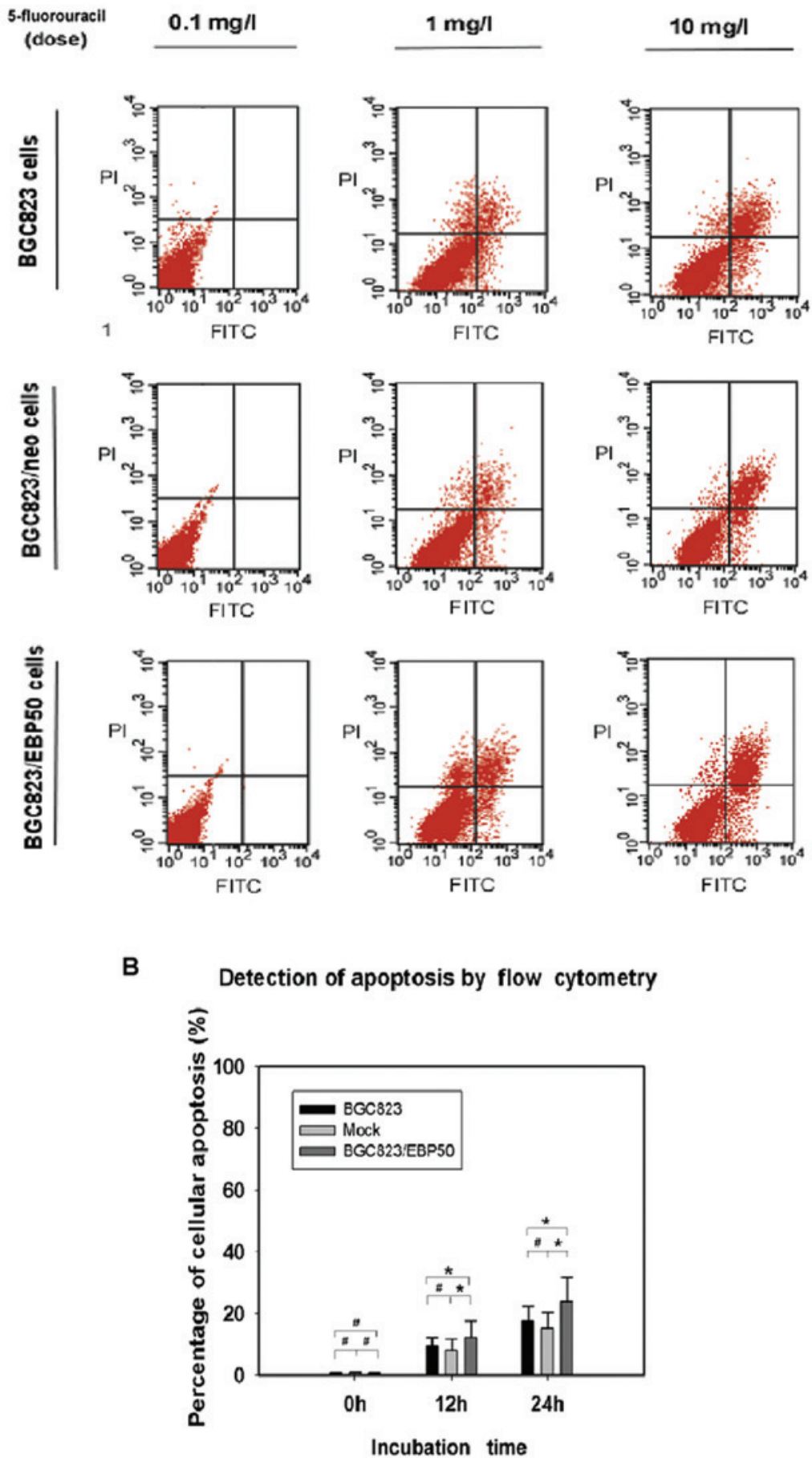

Figure 3. (A) Cellular apoptosis was analyzed by flow cytometry in BGC823/neo and BGC823/EBP50 cells. Annexin/PI staining was performed. The rate of apoptotic cells was defined as the sum of the number of cells in the upper right quadrant and lower right quadrant ( $\mathrm{n}=5$ ). (B) Data are expressed as the mean \pm SE. $\left({ }^{*} \mathrm{P}<0.05 ;{ }^{"} \mathrm{P}>0.05\right)$.

expression. We found that EBP50 overexpression enhanced the apoptosis-inducing effects of 5-FU by MTT assay and Annexin V-FITC/PI staining and flow cytometry. EBP50 gene transfection resulted in the activation of caspase- 3 and -9 in the BGC823 cells, indicating that mitochondrial dysfunction may be involved in EBP50-induced suppression.

The human Bcl-2 gene, located on chromosome 18, is a proto-oncogene in the hematopoietic system (16). The Bcl-2 gene suppresses apoptosis induced by many other factors (17) and the Bax gene encodes a 21-kDa protein, and has $21 \%$ homology with the Bcl-2 gene (18). Overexpression of the Bax gene inhibits the function of Bcl-2 and promotes apoptosis (19). Caspases are crucial mediators of apoptosis. Among them, caspase- 3 and -9 are frequently activated death protease, catalyzing specific cleavage of many key cellular proteins. Caspase- 3 may be the best understood mammalian caspase in terms of its specificity and role in apoptosis (20). In the BGC823 cells transfected with the EBP50 gene, the 
A
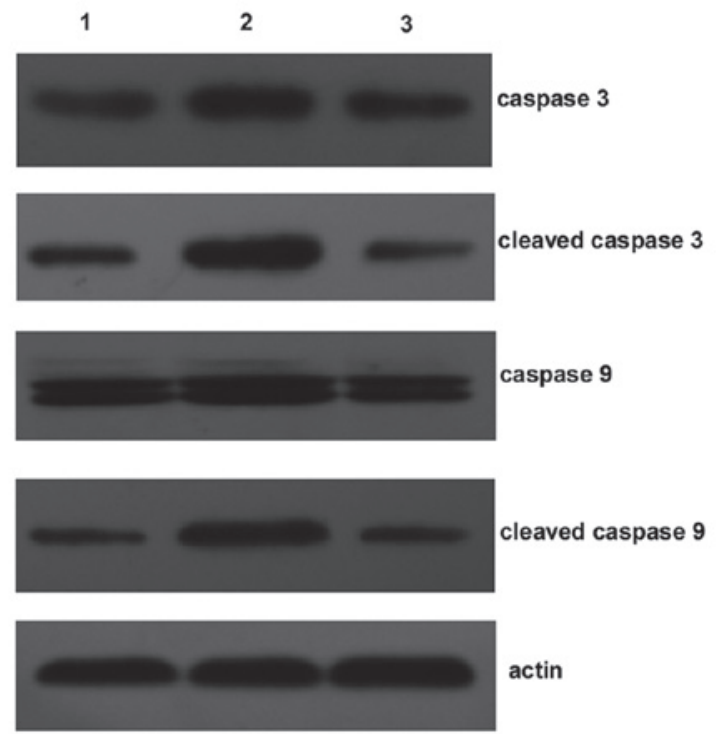

B
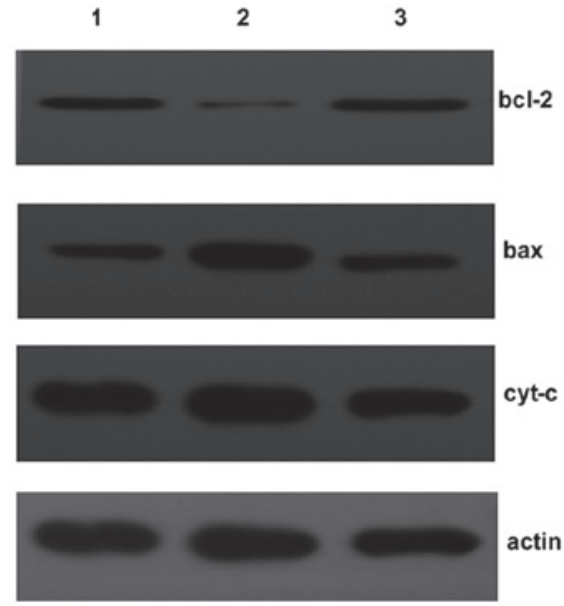

Figure 4. Western blot analysis was performed to detect expression of Bax, Bcl-2, caspase-3 and -9. BGC823, BGC823/neo and BGC823/EBP50 cell lines were treated with 5-FU (10 mg, 24 h). Lane 1, BGC823 cells; lane 2, BGC823/neo cells; lane 3, BGC823/EBP50 cells. Actin was used as the internal control.

expression of Bcl-2 protein was downregulated while Bax was upregulated (Fig. 4B). Subsequently, EBP50 may regulate the death-receptor-associated extrinsic caspase- 8 pathway, resulting in the activation of the mitochondria-associated intrinsic caspase-9 pathway in BGC823 cells. The result may be a co-operative activation of executioner caspase- 3 by both caspase pathways in the end. In agreement with our hypothesis, activated caspase- 3 and -9 were detected in BGC 823 cells transfected with the EBP50 gene in each group (Fig. 4A).

Chemogene therapy has been a viable alternative to conventional chemotherapy combinations for cancer. Chemogene therapy is effective due to the sensitizing of tumor cells to apoptosis by overexpression of a pro-apoptotic protein, followed by the administration of lower doses of chemotherapeutic drugs, therefore reducing systemic toxicity $(21,22)$. Choi et al $(23)$ found that the combination of adenoviral-mediated IFN- $\beta$ gene therapy and 5-FU resulted in tumor regression, apoptosis, and improved survival in an established liver metastasis model of colorectal cancer. This approach may allow for an effective clinical application of chemogene therapy. Treatment with a combination of adenovirus-EBP50 and 5-FU warrants further investigated and may conceivably be beneficial for gastric cancer patients.

In conclusion, we found that EBP50 overexpression enhances the apoptotic effects induced by 5-FU, although mitochondrial dysfunction may be involved in EBP50-induced suppression in gastric cancer cells. These results indicate that a combination of adenovirus-EBP50 and 5-FU may be applied to treat gastric cancer in the future.

\section{Acknowledgements}

This study was supported by the Fundamental Research Funds for the Central University of China (no. 20103020101000194).

\section{References}

1. Hartgrink HH, Jansen EPM, Van Grieken NC and van de Velde CJ: Gastric Cancer. Lancet 374: 477-490, 2009.

2. Ajani JA: Evolving chemotherapy for advanced gastric cancer. Oncologist 10: 49-58, 2005.

3. Ohtsu A: Current status and future prospects of chemotherapy for metastatic gastric cancer: a review. Gastric Cancer 8: 95-102, 2005.

4. Longley DB, Harkin DP and Johnston PG: 5-Fluorouracil: mechanisms of action and clinical strategies. Nat Rev Cancer 3: 330-338, 2003.

5. Song J, Bai J, Yang W, Gabrielson EW, Chan DW and Zhang Z: Expression and clinicopathological significance of oestrogenresponsive ezrin-radixin-moesin-binding phosphoprotein 50 in breast cancer. Histopathology 51: 40-53, 2007.

6. Bellizzi A, Malfettone A, Cardone RA and Mangia A: NHERF1/ EBP50 in breast cancer: clinical perspectives. Breast Care (Basel) 5: 86-90, 2010.

7. Morales FC, Takahashi Y, Momin S, et al: NHERF1/EBP50 head-to-tail intramolecular interaction masks association with PDZ domain ligands. Mol Cell Biol 27: 2527-2537, 2007.

8. Schindelmann S, Windisch J, Grundmann R, Kreienberg R, Zeillinger R and Deissler H: Expression profiling of mammary carcinoma cell lines: correlation of in vitro invasiveness with expression of CD24. Tumour Biol 23: 139-145, 2002.

9. Cardone RA, Bellizzi A, Busco G, Weinman EJ, Dell'Aquila ME, Casavola V, Azzariti A, Mangia A, Paradiso A and Reshkin SJ: The NHERF1 PDZ2 domain regulates PKA-RhoA-p38-mediated NHE1 activation and invasion in breast tumor cells. Mol Biol Cell 18: 1768-1780, 2007.

10. Fouassier L, Rosenberg P, Mergey M, Saubaméa B, Clapéron A, Kinnman N, Chignard N, Jacobsson-Ekman G, Strandvik B, Rey C, et al: Ezrin-radixin-moesin-binding phosphoprotein (EBP50), an estrogen-inducible scaffold protein, contributes to biliary epithelial cell proliferation. Am J Pathol 174: 869-880, 2009.

11. Ledzewicz U and Schattler H: Drug resistance in cancer chemotherapy as an optimal control problem. Disease and continuous dynamical systems-series B 6: 129-150, 2006.

12. Mei M, Ren Y, Zhou X, et al: Suppression of breast cancer cells in vitro by polyamidoamine-dendrimer-mediated 5-fluorouracil chemotherapy combined with antisense micro-RNA 21 gene therapy. J Appl Polym Sci 114: 3760-3766, 2009.

13. Janát-Amsbury MM, Yockman JW, Anderson ML, Kieback DG and Kim SW: Combination of local, non-viral IL12 gene therapy and systemic paclitaxel chemotherapy in a syngeneic ID8 mouse model for human ovarian cancer. Anticancer Res 26: 3223-3228, 2006.

14. Sun Q, Zheng X, Zhang L and Yu J: Smac modulates chemosensitivity in head and neck cancer cells through the mitochondrial apoptotic pathway. Clin Cancer Res 17: 2361-2372, 2011.

15. Miyake H, Hara I, Kamidono S and Gleave ME: Novel therapeutic strategy for advanced prostate cancer using antisense oligodeoxynucleotides targeting anti-apoptotic genes upregulated after androgen withdrawal to delay androgen-independent progression and enhance chemosensitivity. Int J Urol 8: 337-349, 2001. 
16. Tsujimoto Y, Finger LR, Yunis J, Nowell PC and Croce CM: Cloning of the chromosome breakpoint of neoplastic B cells with the $t(14 ; 18)$ chromosome translocation. Science 226: 1097-1099, 1984.

17. Adams JM and Cory S: The Bcl-2 apoptotic switch in cancer development and therapy. Oncogene 26: 1324-1337, 2007.

18. Condorelli G, Morisco C, Stassi G, Notte A, Farina F, Sgaramella G, de Rienzo A, Roncarati R, Trimarco B and Lembo G: Increased cardiomyocyte apoptosis and changes in proapoptotic and antiapoptotic genes Bax and $\mathrm{Bcl}-2$ during left ventricular adaptations to chronic pressure overload in the rat. Circulation 99: 3071-3078, 1999.

19. Duan XX, Ou JS, Li Y, Su JJ, Ou C, Yang C, Yue HF and Ban KC: Dynamic expression of apoptosis-related genes during development of laboratory hepatocellular carcinoma and its relation to apoptosis. World J Gastroenterol 11: 4740-4744, 2005.
20. Boyce M, Degterev A and Yuan J: Caspases: an ancient cellular sword of Damocles. Cell Death Differ 11: 29-37, 2004.

21. Réjiba S, Bigand C,Parmentier C and Hajri A: Gemcitabine-based chemogene therapy for pancreatic cancer using Ad-dCK::UMK GDEPT and TS/RR siRNA strategies. Neoplasia 11: 637-650. 2009.

22. Elliott MJ, Baker JD, Dong YB, Yang HL, Gleason JF Jr and McMasters KM: Inhibition of cyclin A kinase activity in E2F-1 chemogene therapy of colon cancer. Tumour Biol 23: 324-336, 2002.

23. Choi EA, Lei H, Maron DJ, Mick R, Barsoum J, Yu QC, Fraker DL, Wilson JM and Spitz FR: Combined 5-fluorouracil/ systemic interferon-beta gene therapy results in long-term survival in mice with established colorectal liver metastases. Clin Cancer Res 10: 1535-1544, 2004. 